\title{
Is Grit the Best Predictor of University Students' Academic Achievement?
}

\author{
Anthony Akwesi Owusu* \\ Department of Business and Social Sciences Education, \\ University of Cape Coast, PMB, Cape Coast, Ghana \\ Ernestina Larbie \\ Department of Business and Social Sciences Education, \\ University of Cape Coast, PMB, Cape Coast, Ghana \\ Chei Bukari \\ Department of Applied Economics, University of Cape Coast, \\ PMB, Cape Coast, Ghana
}

\begin{abstract}
This paper investigated the predictors of academic achievement of university students in two courses for secondyear students in a public university in Ghana. Using a quantitative design, data were collected from 154 secondyear trainee teachers (for the 2019/2020 academic year), randomly selected from the said public university. The study showed a direct significant relationship between gender, age, motivation to study, and academic achievement in two education courses. Again, age, gender, motivation, and grit were significant predictors of student academic achievement in two education courses, with grit as the best predictor contributing to $67 \%$ variability in student academic achievement. Based on the results, the study recommended that university authorities, among other things, should, through their academic and quality assurance sections, determine students' grit levels, identify those likely to have challenges, initiate appropriate measures to enhance perseverance and retention, thereby, improving academic achievement.
\end{abstract}

Keywords: grit, economics, office management, academic achievement, motivation

DOI: $10.7176 / \mathrm{JEP} / 11-29-08$

Publication date:October $31^{\text {st }} 2020$

\section{Introduction}

Developing literature shows that many factors influence the academic achievement of university students which also, in turn, reflect student completion rates in environments of higher learning. These determinants, researches have shown, are usually responsible for student retention, perseverance, completion, and achievement in a particular programme (Egdorf, 2013). In some subject areas, students can persevere and graduate on time whereas, in other study areas, graduation rates have been rather sluggish. As we know, high academic achievement is the single reason why students learn in pursuit of their academic programmes till graduation (Egdorf, 2013). Over the years, more attention was focused on the many variables responsible for student's academic achievement to understand, appreciate, and improve student perseverance, and academic achievement (Roth, et al., 2013). A look at these studies shows that they were conducted outside Ghana thus, making it unusable in terms of application in the local context of Ghana. This geographical gap necessitated the conduct of this study to provide germane information in Ghana.

The current study, therefore, focused on examining the best predictor of academic achievement among motivation to study, age, and grit of students in the two courses. Economics is one of the few subject areas in which students find extremely difficult to pass. It is one of the major courses offered by trainee teachers in the field of Economics. Office Management is also a course of study made of two modules packaged together designed to prepare and equip students with the knowledge, skills, experiences and the suitable mental and professional orientation for efficient management of the office and its functions. The two courses were chosen because they represent core curricula for student trainee teachers who are receiving training to teach Economics and management in senior high schools in Ghana. Additionally, in content, the two courses are interconnected in that whereas Economics studies the management of scarce resources, Office Management focuses on management and administration of office resources. The study's objectives were to examine if a significant relationship existed between student grit levels and their academic achievement in two courses, and also to investigate the best predictor of academic achievement relative to gender, age, motivation to study and grit.

\subsection{Literature Review}

\subsubsection{Theoretical Basis of the Study}

The theory of motivation gives multiple frameworks which are key in understanding student behaviours in school. 
Motivational theories are concerned with the energization and direction of behaviour. While Duckworth et al (2007) do not straight away connect grit to motivation, they merge the energy and focus in trying to define grit. They conceptualize grit to involve perseverance in the face of difficulties and still sustaining effort, showing interest notwithstanding downturns, hardship, and moving towards achievement. Motivation is denoted as the "why am I doing this?" of a behaviour. Motivation can be seen also as a response that rationalizes conscious use of time, energy, and capacities of one activity over another. Motivation encapsulates individual energies expended in learning and working efficiently to achieve one's dreams. It comprises issues touching on emotions, cognitive, and behavioural dimensions, which intermingle thereby developing enduring classroom behaviours. Even though gender and grit, in this study are not clearly conceived as motivational constructs, they qualify to be categorized under motivation since one's motivation may be influenced by gender and grit (Flanagan \& Einarson, 2017).

\subsubsection{Determinants of Student Academic Achievement}

A substantial body of literature which identifies factors that cause or contribute to student achievement exists. However, much of it is focused on the relationship between achievement and traditional cognitive measures, such as high school GPA (HSGPA) and scores on standardized tests. In most studies, student perseverance has been attributed to their grit level, which is fast gaining popularity in research (Akin, \& Arslan, 2014; Harms, 2016). Since then, grit has been studied extensively in various fields other than in education (Maclaren, 2015; Nishikawa et al., 2015). Some of the studies aimed to establish how kids could be helped to be grittier to move out of poverty (Bengtson, 2013). Some of these studies have posited that grittier students include those who are not easily discouraged by setbacks, those students who maintain focus on a project, work hard, try always to complete tasks, and are diligent (Duckworth \& Quinn, 2009). In contrast, less gritty student behaviour descriptions are varied. Some of them have been described as unfocussed in the face of new projects and challenges, being indecisive in selecting a goal, and the impossibility of sticking to a focus on long-term assignments. Despite its ability to forecast student's academic achievement at any level of learning, grit has not been sufficiently studied at the university particularly among undergraduate Nature of Economics students.

To identify some of the additional predictors of achievement, researchers have explored the second line of inquiry in the examination of non-cognitive factors (Akos, \& Kretchmar, 2017; Nelson, 2016). One of the nocognitive factors that have received increased focus during the last few years is grit. Grit is considered by many psychologists as performance character strength, drawn upon to achieve one's potential in a particular challenge (Nishikawa et al., 2015). Research on grit has been mainly conducted by Angela Duckworth. She expresses grit as, "perseverance and passion for long term goals" (Duckworth et al., 2007, p. 1087). Grit involves working persistently and vigorously towards a challenging goal, sustaining effort and keeping an unabated interest over long periods despite failure, holdups and obstacles, and phases of stability in the course of progress. Gritty individuals employ resilience to stay on track to reach their goals, contrary to low gritty individuals who get easily fed up or disappointed and as such, easily give up effort or choose alternative actions (Duckworth et al., 2007). Grit is considered a personal quality common in leaders, and an important antecedent of success and excellence in every domain regardless of giftedness or talent (Duckworth \& Yeager, 2015).

To date, researchers have focused on the part grit plays forecasting classroom achievement among postsecondary students (Mason, 2018) but not in a teacher education training programme like this study seeks to achieve. Researchers have also investigated the role of grit in teacher achievement to understand what may lead some in the profession to outperform others (Duckworth \& Quinn, 2009; Von Culin, et al., 2014). Yet, there seem to be no studies focusing on determinants of academic achievement with age, gender, motivation, and grit as the explanatory variables among university students in Ghana. Results on a study of this kind may inform stakeholders in higher education on measures to take to improve achievement as well as promote persistence.

Prior research had been definite on the fact that student scores and cleverness are the most dependable matrix of student perseverance in higher institutions of learning (Harms, 2016; Yang, 2019). Yet, there appear to be abundant studies that have shown that capabilities such as aptitude, cleverness, and IQ do not significantly influence academic achievement or future school success (Grey, 2019; Jacobs, 1959; Tian, \& Sun, 2019).

It has been debated that academic achievement is the result of a mixture of inborn flair and effort (Abuhassan $\&$ Bates, 2015). It has been strongly argued that grittier persons work harder and longer and are more disposed to engaging in the cautious practice to foster school success or academic achievement (Ivcevic \& Brackett, 2014). Achievements are limited by innate factors and cognitive skills and require deliberate efforts on the part of the individual to change or improve particular characteristics of achievement. Grittier individuals are usually tenacious and industrious; people are not easily dispirited by impediments (Doleck et al., 2018). On the other hand, less gritty persons are less determined or less assiduous (Perez, 2015). They are often than not, swayed by new happenings and are not able to set lasting goals. Besides, they usually lack the impetus to concentrate on enduring projects.

Two hypotheses were formulated and tested in this study and these were: 
1. $\mathrm{H}_{0}$ : There is no significant relationship among students' grit levels, age, and motivation on academic achievement in 'Nature of Economics' and 'Office Management' among second and third year students in a public university.

$\mathrm{H}_{1:}$ : There is a significant relationship among students' grit levels, age, and motivation on academic achievement in 'Nature of Economics' and 'Office Management' among second and third year students in a public university.

2. $\mathrm{H}_{0}$ : Grit level, age, gender, and motivation to study do not significantly affect students' academic achievement in 'Nature of Economics' and 'Office Management' among second and third year students in a public university.

$\mathrm{H}_{1}$ : Grit level, age, gender, and motivation to study significantly affect students' academic achievement in 'Nature of Economics' and 'Office Management' among second and third year students in a public university.

\subsection{Methodology}

1.3.1 Research Goal

The purpose of this research was to investigate whether grit was the best predictor of academic achievement in two courses among undergraduate students in a public university context.

\subsubsection{Sample and Data Collection}

The sample comprised 154 undergraduate students who were offering Nature of Economics and Office Management as part of their training programme as teachers. The sample consisted of students between the age ranges of $18-24$ years who were evenly distributed across level 200 and level 300 students for the 2019/2020 academic year. As required by ethical standards, a group informed consent form was given to students and all of the respondents of the questionnaire. Respondents were taken through 5-minute recruitment presentation. They were schooled on the rationale for the study, its purpose, the possible benefits and dangers, the role participants would be required to play, and the incentives students would be entitled in participating in the study. Participants were given the liberty to withdraw at any stage of the research process. Participants filled and signed the consent forms in groups which were later collected.

\subsubsection{Data Collection Instrument}

The researchers adapted the instrument from Duckworth, Peterson, Matthews and Kelly (2007). We divided the instrument into two main sections: section '1' and '2'. Section 1, which comprised six items, solicited biographic information of respondents. Issues such as respondents' gender, age, and programme were taken from the students. Besides, we requested students to indicate their registration numbers and their motivation to study either economics or office management. The last item on this section of the instrument, which students were not supposed to indicate anything, was their grade in the course. Researchers completed this section of the questionnaire to ensure objectivity by avoiding situations where students write grades that did not reflect their actual performances. We obtained the student academic achievement from the End of First Semester Examination Scores for the 2019/2020 academic year in the two courses.

The second section of the instrument touched mainly on the grit scores of students. It comprised 12 items, which were measured on a five-point Likert scale ranging from, 'very much like me' =5; 'mostly like me' $=4$; 'somewhat like $\mathrm{me}^{\prime}=3$; 'not much like $\mathrm{me}^{\prime}=2$; and 'not like me at' $=1$. For these scales, we requested the respondents to rate their grit levels based on the item statements. Students responded to four items on their consistent interests ('I often set a goal but later choose to pursue a different one'). Also, other four items related to student perseverance of effort ('I finish whatever I begin'), and the last four items focused on their hard work ('I am a hard worker').

As instruction, students were to keep track of their total score in the last column and their grit score was to be the average of their responses to each question, between '1' and '5'; with ' 1 ' being, 'not at all gritty' and '5' being, 'extremely gritty'. So, an individual who had an average score between $1.00-1.92$ was, 'not gritty at all', while those who had scores between $2.00-2.92$ were said to be 'somehow gritty'. Again, those with an average score between $3.00-3.92$ were said to be 'gritty', while those with an average grit score between $4.00-5.00$ were deemed to be 'extremely gritty' on the grit scale scoring sheet (Rojas et al., 2012).

1.3.4 Data Collection Process

Data collection consisted of a 10- to 15-minute completion of a face-to-face questionnaire by students. Before actual data collection, the investigators pilot-tested the instruments on 30 students in an analogous university: The University of Education, Winneba with similar characteristics to establish internal consistency of the items. The researchers obtained a Cronbach alpha reliability coefficient of 0.867 on the grit items, showing that the individual items were internally cohesive on the grit construct. Also, measures were taken by the researchers to ensure validity. Validity is the amount of systematic or built-in error in the questionnaire (Wong et al., 2012). The instrument for data collection was tested to ensure validity. Translational validity of the questionnaire was established through the opinions of some doyens in education on the extent to which the theoretical constructs in the questionnaire reflect the literature (Bolarinwa, 2015). To ensure this, the researchers gave the instrument to two experts in 
psychology and teacher education to assist in its refining (Wong, et al., 2012).

The researchers were personally involved in the collection of the data. Researchers told participants not to answer any question they felt uncomfortable responding to. They were given the right to ask questions at any time during the survey as long as they deemed those questions relevant. All students who completed the questionnaires and returned same were incentivized with 20 Ghana Cedis. To obtain scores on students' achievement, the end of first-semester examination scores for students for the 2018/2019 academic year (in the two courses) were collated and written against the questionnaires of the students concerned. Since the researchers taught those courses, they could juxtapose the responses on the questionnaire against the true scores (in terms of achievement) of the students. 1.3.5 Analyzing of Data

Before data analysis, we conducted a series of statistical tests to ensure that we satisfied the requirements for using parametric tools. To avoid drawing erroneous conclusions, the necessary post estimation assumptions of normality, model specification, heteroskedasticity, and multicollinearity were performed with no observed violations as shown in Table 1.

Table 1. Data distribution on homoskedasticity, omitted variable bias, and multicollinearity

\begin{tabular}{|l|l|}
\hline Homoscedasticity & 0.9215 \\
\hline Omitted variable bias & 0.0453 \\
\hline Multicollinearity (Mean VIF) & 1.43 \\
\hline $\mathrm{N}$ & 154 \\
\hline $\mathrm{F}(6,148)$ & 32.46 \\
\hline Prob $>$ F & 0.0000 \\
\hline R-squared & 0.7556 \\
\hline Adj R-squared & 0.7323 \\
Root MSE & 0.33442 \\
\hline
\end{tabular}

The Kolmogorov-Smirnov Shapiro Wilk test showed data normality: $\mathrm{D}(152)=0.83, \mathrm{P}=0.321>0.05$. Again, the Ramsey reset test using powers of fitted values showed no omitted values. Since the F value was less than the critical value, $(\mathrm{F}<32.46)$ we failed to reject the null hypothesis of the correct specification. To test for heteroskedasticity, the Breusch-Pagan/ Cook Weisberg test under the null hypothesis of constant variance produced $p$-value greater than alpha $(\mathrm{p}>\alpha$ Prob $>$ chi $2=0.9215)$ showing that the data was homoscedastic, implying that the error term is constant variance across the independent variables. Lastly, since the mean-variance inflation factor $(\mathrm{VIF})$ was less than 10 , (Mean VIF $=1.43)$ the data was devoid of multicollinearity among the independent variables. These statistical testing outcomes warranted the use of multiple regression and inferential statistical tool.

We computed summary scores for all the grit variables using descriptive statistics for all demographic and academic variables. The sample size was small and therefore, it did not permit us to have tolerable levels of statistical power to detect existing relationships between the explanatory and criterion variables. We gave age a categorical coding (young/elder) of between 18 and 28 or 29 and above. We used the Point-Biserial correlation to analyze Hypothesis 1 whereas we used multiple regression to analyze Hypothesis 2 . Before the analyses, making sure the requirements for normality of data, model specification, homoscedasticity, and multicollinearity requirements were met before the use of the inferential statistics.

\subsection{Findings / Results}

\subsubsection{Profile Information of Respondents}

The profile segment of the survey instrument contained questions about students' age, gender, motivation to study, and grade level in the course.

1.4.2 Psycho-educational variable.

We measured grit using the Short Grit Scale by Duckworth et al., 2007). Students responded to how much four items about their consistent interests ('I often set a goal but later choose to pursue a different one'). In addition, there were four items touching on their perseverance of effort ('I finish whatever I begin'), and finally, four items focusing on their hard work ('I am a hard worker'). All the 12 items were described on a 5- point Likert scale, ranging from not like me (1) to very much like me (5). Due to the robustness of the instrument, researchers did not conduct any reliability test on it before final administration. Student academic achievement was gotten from the End of First Semester scores for the 2019/2020 academic year in the two courses. We computed summary scores for all the grit variables using descriptive statistics for all demographic and academic variables. Clearly, the small sample size did not permit the researchers to have tolerable levels of statistical power to detect existing relationships the explanatory and criterions variables. Age was given a categorical coding (young/old) of between 18 and 28 or 29 and above. The Pearson Product Moment correlation was used to analyze hypothesis 1 whereas a multiple regression was used to analyze hypothesis 2 .

Hypothesis 1: There is a significant correlation between age, motivation, and academic achievement in the two courses. 
This hypothesis sought to find the association among age, motivation, and academic achievement. Since linearity between the variables was established, researchers used the Point-Biserial Correlation, a non-parametric tool to analyse the data. Our data indicated which of the opposing hypotheses was most likely to be true. The null hypothesis of no correlation present in the population was tested against the alternative that there is the presence of monotonic relationship at 0.05 significant level. Table 2 shows the results obtained on the hypothesis. To test for the association among age, motivation, and academic achievement, the study estimated equation (1) under the hypothesis that: there is no statistically significant correlation among age, motivation, and academic achievement. Table 2 presents the result on the association among these variables using Ordinary Least Square (OLS). Table 2. Point-biserial correlation among students' achievement, age, and motivation

\begin{tabular}{|l|l|l|l|l|}
\hline & Effect Size (Achievement) & Estimate & {$[95 \%$ Conf. } & Interval] \\
\hline Age & Point-Biserial r & -.1517402 & -.0829133 & -.0204085 \\
\hline Motivation & Point-Biserial r & .1004842 & .0693691 & .1312949 \\
\hline
\end{tabular}

Field Data, 2019; $\mathrm{n}=154$.

In Table 2, we analysed whether there is a correlation among age (young $=1$ and elder $=2$ ), motivation to learn (extrinsic $=1$ and intrinsic $=2)$ and academic achievement (measured on a scale of $1-100)$. From the results, elder students tend to have higher academic achievement than younger males $r \mathrm{pb}=.71, \mathrm{p}<.05$. Also, intrinsically motivated students tend to perform academically than their counterparts who are extrinsically motivated, though there is a significant positive correlation among age, motivation, and academic achievement. For instance, the association between age and achievement is moderately positive $(r=0.5474)$ in the same manner as motivation is also positively correlated with achievement $(\mathrm{r}=0.5931)$.

\subsubsection{Assumption Tests for Regression}

Since linearity was established, the necessary assumption tests were run to warrant the use of multiple regression. These assumptions included normality of dependent variable, heteroskedasticity (variance of the dependent variable is not dependent on the independent variables), and the dependent variables were devoid of multicollinearity (the correlations among independent variables were not so high). The Tolerance and VIF values helped to determine the multicollinearity assumption was met. The variance inflation factor (VIF) and tolerance are two strictly related statistical procedures for establishing collinearity in multiple regression. They are based on the R-squared value obtained by regressing a predictor on all of the other predictors in the analysis. Tolerance level is the reciprocal of VIF. Table 3 shows the tolerance and the VIF report of the study.

Table 3. The tolerance and the VIF report prior to regression analysis

\begin{tabular}{|l|l|l|}
\hline Variable & VIF & Tolerance (1/VIF) \\
\hline Grit & & \\
\hline Low & 1.46 & 0.685844 \\
\hline Moderate & 1.51 & 0.660650 \\
\hline High & 1.67 & 0.598623 \\
\hline Age & 1.01 & 0.985549 \\
\hline Male & 1.01 & 0.987340 \\
\hline Motivation & 1.01 & 0.992738 \\
\hline Mean VIF & 1.38 & \\
\hline
\end{tabular}

In Table 3, it is clear that the VIF values are less than 10. A rule of thumb commonly used in practice is that if the VIF is less than 10, we have low multicollinearity. In our case, with values around 1, we are justified to proceed with a regression analysis. By inference, the reciprocal of the various VIF values show no violations to multicollinearity.

Hypothesis 2: Grit level, age, gender, and motivation to study do not significantly affect students' academic achievement in 'Nature of Economics' and 'Office Management' among second and third-year students in a public university.

We formulated this hypothesis to investigate the factors that significantly predict students' academic achievement using the hierarchical multiple regression analysis. To test the hypothesis, the null hypothesis, $\mathrm{H}_{0}$ that grit level, gender, and motivation to study significantly affect students' academic achievement in the two courses in the population against the alternative hypothesis, $\mathrm{H}_{1}$ grit level, age, gender, and motivation to study significantly affect students' academic achievement in the two courses was tested at 0.05 significant level. The student achievement scores were obtained from their end of the first-semester examination for the 2018/2019 academic year, which was rated on a hundred-point scale. Students who scored below $50 \%$ were deemed to have performed poorly whereas those who scored $75 \%$ or above were said to have done very well. Table 4 shows a summary of output obtained from the field data. 
Table 4. Effect of grit level, age, gender, and motivation to study on student course achievement

\begin{tabular}{|c|c|c|c|c|}
\hline & Achievement $(\log )$ & \multirow{2}{*}{$\begin{array}{l}\text { Standard } \\
\text { Error }\end{array}$} & \multicolumn{2}{|c|}{ Confidence Interval } \\
\hline Variable & Coef. & & Lower Limit & Upper Limit \\
\hline \multicolumn{5}{|c|}{ Grit (base $=$ very low) } \\
\hline low & $\begin{array}{l}.293 * * \\
(2.31)\end{array}$ & .0690818 & .0411366 & .3120171 \\
\hline Moderate & $\begin{array}{l}.846 * * * \\
(6.90)\end{array}$ & .0665098 & .249688 & .9104831 \\
\hline High & $\begin{array}{l}.870^{* * * *} \\
(6.82) \\
\end{array}$ & .0627011 & .3686047 & .9144656 \\
\hline \multicolumn{5}{|c|}{ Age (base $=$ young) } \\
\hline Elder & $\begin{array}{l}.581^{* * * *} \\
(6.16)\end{array}$ & .0411952 & .1560727 & .676056 \\
\hline \multicolumn{5}{|c|}{ Gender $($ base $=$ female $)$} \\
\hline Male & $\begin{array}{l}.388^{* *} \\
(2.37)\end{array}$ & .0959877 & .2115406 & .587923 \\
\hline \multicolumn{5}{|c|}{ Motivation (base $=$ extrinsic) } \\
\hline intrinsic & $\begin{array}{l}.200 * * \\
(2.29) \\
\end{array}$ & .0959828 & -.0805853 & .2957782 \\
\hline Constant & $\begin{array}{l}1.361 \\
(1.51)\end{array}$ & .1301504 & .1443988 & 2.340589 \\
\hline
\end{tabular}

$* * * \mathrm{P}<0.001, * * \mathrm{P}<0.05, * \mathrm{P}<0.1$. t-statistic in brackets; $\mathrm{n}=154$; Field Data, 2019.

On grit level in Table 4, the base category variable was very low grit level. Therefore, compared to a student with very low grit level, a student with low grit level, all other factors being constant, increases his/her academic achievement by 0.293 , indicating statistically significant outcome at five per cent showing the relevance of the variation. Again, as observed, that compared to a student with a very low grit level, a student with moderate grit level increases their class achievement by 0.846 at one per cent significance showing the relevance of the variation. Finally, compared to an individual with a very low grit, a student with high grit level, all other factors held constant, increases his/her class achievement by 0.870 at one per cent significance showing the relevance of the variation. Clearly, the results show that grit contributes about $66.7 \%$ variability in academic achievement, making it the best predictor of academic achievement while $33.3 \%$ of the variability in academic achievement is attributable to age and motivation to study.

On age and achievement with the young student as the base category, it is observed that compared to a young student, an elder student, all other things being constant, increases his/her class achievement by 0.581 . This outcome is significant at one per cent, showing the relevance of the variation. Deductively, the outcome suggests that age is positively related to academic achievement. As can be gleaned from Table 4, female denoted the base category variable. It shows that compared to a female student, a male student, all other factors held constant, increases his academic achievement by 0.388 at five per cent significance level, showing the relevance of the variation. Here, it has been found that male students, compared to their female counterparts, irrespective of their grit levels, have higher academic achievement than females. On motivation and academic achievement, extrinsic motivation was taken as the base category variable. Compared to an individual with extrinsic motivation, a student with intrinsic motivation, all other factors held constant, increases his/her academic achievement by 0.200 at five per cent significance, showing the relevance of the variation. By deduction, intrinsic motivation, rather than extrinsic motivation, increases academic achievement. In Figure 1, we show the marginal effect of Age, motivation and Grit on students' achievement. Evidently, in terms of age, the elder students are doing better than the younger students while intrinsic motivation engenders students' achievement compared to extrinsic motivation. High levels of grit promote high students' achievements. 

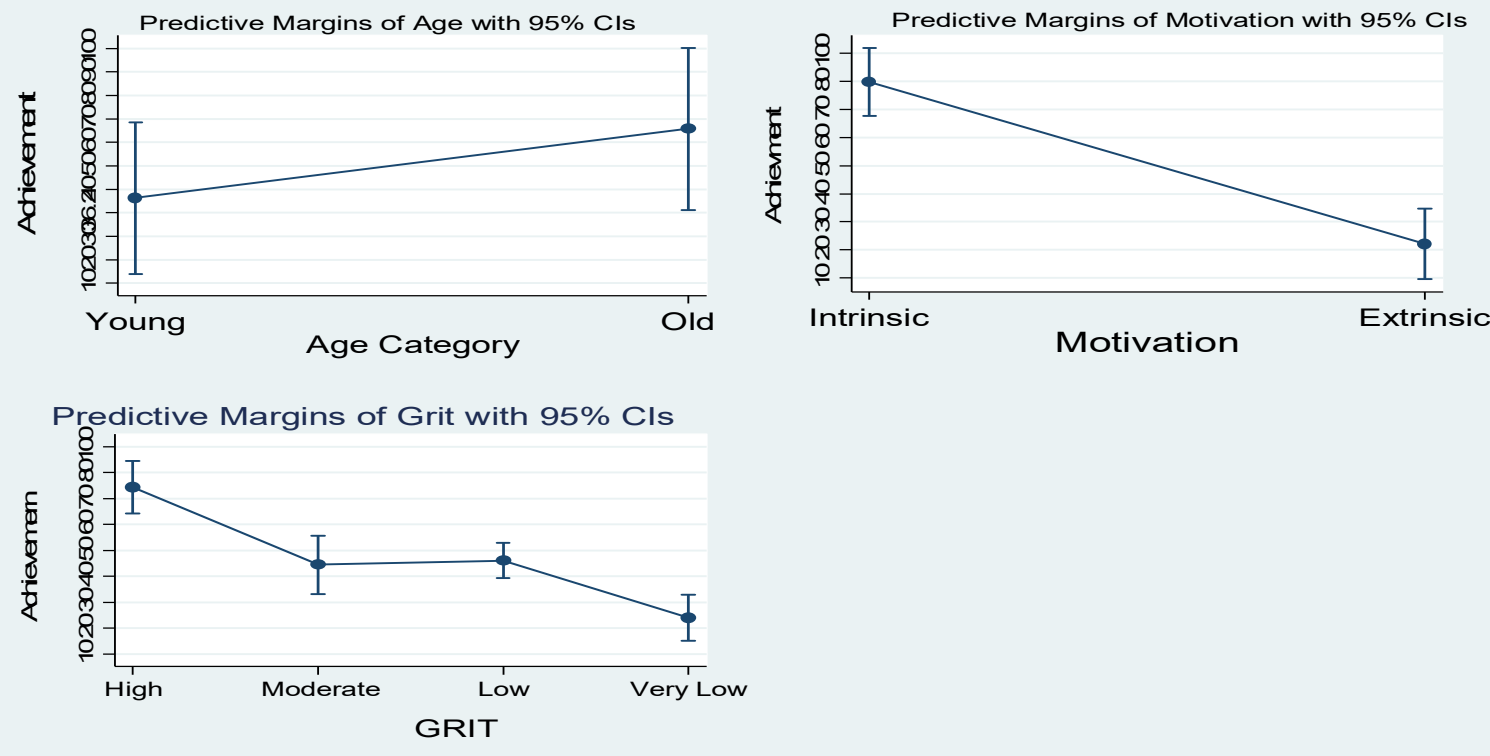

Figure 1. Marginal Effect of Predictors and the Response Variable.

\subsection{Discussion}

This study investigated whether grit was the best predictor of academic achievement in two courses among undergraduate university students in Ghana. From hypothesis one, elder students and intrinsically motivated students had significantly higher academic achievement than in younger, and extrinsically motivated students. Perhaps, the outcome of the elder students is due to their resilience and resolution to pursue their goals and aspirations. Elder students tend to be passionate about achieving their academic goals and the desire in them provides the impetus to set their priorities right (Bouffard, 2017). By inference, we can conclude that intrinsically motivated students also operate with positive mindsets, dovetailing into their having positive attitudes toward learning. While many of the previous studies indicated no gender differences in grit (Ali \& Rahaman, 2012; Duckworth et al., 2007; Duckworth \& Quinn, 2009), this present study found a significant positive correlation among age, motivation, and academic achievement. In other studies, unlike this one, male students were found to be grittier than females (Ali \& Rahaman, 2012), even though other studies have shown contrary result (Jaeger et al., 2010; Christensen \& Knezek, 2014). The outcome of the current outcome could be attributed to the general notion that males appear more capable in fields that require increased use of grit than females. Notwithstanding this, there is the argument today that what men can do, women can do even better given the chance. Following the study by Duckworth et al. (2007), many other research studies, like this one, have examined the correlation between grit and age and found that a positive correlation between grit and age (Cupitt \& Golshan, 2015; Griffin et al., 2016). Accordingly, the older an individual is, the higher their level of grit. Therefore, the present study appears to suggest that elder students are more likely to have higher grit levels compared to their younger colleagues the reason for which they out-perform latter in terms of academic achievement. Perhaps, this could be explicated by the perception that older students are more likely to have overcome more challenges and setbacks in life in the past and therefore, were in a better position to persevere. Despite this, there is still research, which opposes this finding by suggesting no variation in grit scores depending on the gender and age of individuals (Ali \& Rahaman, 2012; Duckworth et al., 2007; Duckworth \& Quinn, 2009).

The study has shown that grit, which is considered a noncognitive factor, plays a critical role in the learning success of students. It has attracted increasing attention from both researchers and practitioners as a vital ingredient for classroom achievement and used widely to make people appreciate individual success and performance in various fields. Yet, past empirical research has revealed contradictory findings on the association between grit and academic achievement. The purpose of this study was to examine the best predictor of students' achievement among explanatory variables such as age, gender, motivation to study, and grit. This study has shown that grit is the best predictor of student academic achievement. We specifically attended to grit as an overall construct and as a two-dimensional construct (i.e., consistency of interest and perseverance of effort).

Concerning the issues identified in the literature around predictors of students' academic achievement, this study highlights certain interesting points worth discussing. Although the small sample size of the study means it impracticable to make claims about the commonality of the issues, the study raises significant questions that warrant further exploration. There has been a well-established emphasis on the relationship between achievement and traditional cognitive measures such as students' Grade Point Averages (GPA) and their standardized tests 
scores (Atkinson \& Geiser, 2009). In the same way, this study has revealed a strong direct relationship between grit and student academic achievement in the two courses for the teacher trainees, implying grittier students have high academic achievements compared to low gritty students. Indeed, grit provides incremental predictive validity on students' achievement, and the study has revealed. Again, grit levels are positively correlated to academic achievement, implying that the higher a students' grit level, the more persevering they are, and thus having high academic achievement (Beyhan, 2016; Beyhan, \& Dilmac, 2016; Maclaren, 2015). Grit is seen therefore as key to improving student academic achievement because it is that which drives student perseverance (Nishikawa et al., 2015). This outcome supports the idea that grittier students include those who are not easily discouraged by setbacks. They are resolute and diligent to the extent that they maintain a focus on projects assigned to them, they work hard, and try always to complete tasks (Duckworth \& Quinn, 2009).

This study has shown that grit, age, gender, and motivation (Flanagan \& Einarson, 2017) are strong direct predictors of academic achievement in contrast to previous findings which pointed rather to trait-like persistence as related to high academic achievement (De Vera et al., 2015). From the results, students with intrinsic motivation tend to focus more on learning by making persistent efforts in learning. As a result, they can achieve better in their academic work. So, to enhance student motivation to learn, they have to persevere with the effort to succeed in school. Also, since age is positively related to academic achievement, elder people should be encouraged to pursue programmes because this is likely to enhance their academic achievement. It came to light that those male students compared to female counterparts irrespective of grit levels, had higher academic achievement. Is it the case that men always want to succeed in the things they do? Intrinsically motivated students score higher in their academic achievement than extrinsically motivated students.

\subsection{Conclusion}

The study focused on the determinants of academic achievement of university students with a focus on grit, age, gender, and motivation. The claim that grit is a better predictor of academic achievement has been withheld by this study. Grit was found as the most critical driver determining academic achievement. It undoubted that grittier students are dedicated to goals, and they can withstand impediments, failures and challenges that come with learning. Grit has the strongest positive relationship with achievement (Beyhan, 2016). In addition to grit, age and motivation are also key determinants of academic achievement. Also, age is a key factor that is positively related to academic achievement of students. Intrinsically motivated students tend to have higher academic achievement compared to extrinsically motivated students. As far as this study is concerned, it is important to leverage these variables grit, age, and motivation to improve student learning (Muenks et al., 2018).

In sum, the study has demonstrated that there is a basis for research and practice in grit and its antecedents in education. By the results, the study has shown that grit is a critical ingredient for student academic achievement. The dissimilar levels of academic achievement of students are largely attributable or explained by grit. Per its results, the study has also shown that the two components of grit - perseverance of effort and consistency of interests largely account for changes in student academic achievement. By implication, when students persevere with efforts, they are likely to succeed in their academic output. Again, it is clear that developing consistency if interest puts the individual student on the path to academic success. Indeed, this study has shown that it is not unusual to for students with less consistency of interest and perseverance of effort (low gritty individuals) to record low academic achievement.

\subsubsection{Suggestions}

Given the findings, higher education institutions should, through their academic and quality assurance sections, use grit levels to forecast students who are less likely to succeed in their study, and accordingly, put remedial measures in place to improve retention, perseverance, and academic achievement of all students. Also, since grit is a personality trait, universities should task their personnel in psychology to nurture students' grit and teach the concept to them in consonance with the belief that it increases with age. Further, teacher-training departments within universities must mount courses on grit as part of the teacher education programmes to 'grow trainee teachers' on this concept, more especially because these teachers, on the teaching field, may be required to help other students to deal with grit issues. Additionally, university authorities should encourage faculty members could also adopt students with less grit levels and mentor them to be successful as an intervention measure to improve retention, perseverance and class achievement. Finally, curriculum experts should help students come out with explicit goal-setting strategies aimed toward goals achievement. This can increase students' grit levels thereby enhancing persistence and academic achievement.

\subsubsection{Suggestions for future research}

First, In the light of the flaws, we recommend that future research on grit should involve students from different institutions, with a diverse sample of ethnic backgrounds, ages, genders, programme areas among others to fully represent the population and obtain more reliable results. In this regard, large scale studies, with large sample sizes should be conducted to boost statistical power and generalizability of the findings since this situation may guarantee research outcomes that are more decisive and robust thereby, furnishing educators with vital information 
about the construct of grit and which groups of students should focus on their grit development. To deal with the self-report measure flaw, we recommend that future researchers expand the scope of their studies by incorporating a wider range of measures and tools such as phenomenological, neuropsychological/physiological, and behavioural and related to provide a more objective conclusion. Finally, to deal with the flaw connected to the use of a crosssectional descriptive approach, future researchers should consider expanding their approaches by integrating a combination of approaches to study the concept of grit and academic achievement. In this direction, more longitudinal studies on the subject can be conducted to holistically delve into grit.

1.6.3 Limitations

Although the study came out with significant findings in terms of grit and its strong correlations with other constructs related to student success, the study is not without their limitations. First, this study was conducted in one institution, a University in the Central region of Ghana, which has implications for the generalizability of the results. Again, connected to generalizability is the small sample size used for the study. The small sample size has adverse implications on predictability and statistical power since only one public university was used. Therefore, generalizing findings to cover all public universities in Ghana cannot be tenable. Second, the study used a selfreport measure to gather data on students' grit level. This has implications for the accompanying social desirability effects. Third, the two data sets collected on academic achievement in the two courses could have different degrees of reliability. Lastly, the finding of this study cannot be generalized because of the usual problems associated with concluding cross-sectional studies.

1.6.4 Acknowledgements

We would like to thank all students who took time off their busy academic schedules to respond to our instruments. We are also grateful to the Directorate of Policy and Quality Assurance (DaPQA) of University of Cape Coast for allowing us to collect data while lectures were ongoing. We are thankful.

\section{References}

Abuhassan, A., \& Bates, T. C. (2015). Grit: Distinguishing effort persistence from consciousness. Journal of Individual Differences, 36, 205 - 214. https://doi.org/10.1027/1614-0001/a000175.

Akin, A., \& Arslan, S. (2014). The relationships between achievement goal orientations and grit. Education and Science, 39, 267 - 274. https://doi.org/10.15390/EB2014.2125.

Akos, P., \& Kretchmar, J. (2017). Investigating grit at a non-cognitive predictor of college success. The review of Higher Education, 40, 163 - 186. https://doi.org/10.1353/rhe.2017.0000.

Ali, J. \& Rahaman, A. (2012). A comparative study of grit between male and female fencers of manipur. Shield 7 32-36.http://sujo-old.usindh.edu.pk/index.php/THE-SHIELD/article/download/1017/954.

Anderson, C., Turner, A. C., Heath, R. D., \& Payne, C. M. (2016). On the meaning of grit...and hope... and fate control...alienation....and locus of control...and self-efficacy...and...effort optimism...and... The Urban Review: Issues and Ideas in Public Education, 48(2), 198 - 219. https://doi.org/10.1007/s11256-016-0351-3.

Atkinson, R. C., \& Geiser, S. (2009). Reflections on a century of college admissions tests. Educational Researcher, 38(9), 665-676. https://doi.org/10.3102/0013189x09351981.

Bengtson, E. (2013). How Children Succeed: Grit, curiosity, and the hidden power of character by Paul Tough. Journal of School Choice, 7(1), 100 -102. https://doi.org/10.1080/15582159.2013.759845.

Beyhan, Ö. (2016). University students grit level and grit achievement relation. Social Sciences and Education Research Review, 3(2), 13 - 23. https://sserr.ro/wp-content/uploads/2016/12/3-2-13-23.pdf

Beyhan, O., \& Dilmac, B. (2016). Grit levels of teacher training programme students in terms of different variables. In Proceedings of Teaching and Education Conferences (No. 3906176). International Institute of Social and Economic Sciences. https://doi.org/10.20472/tec.2016.003.001.

Bolarinwa, O. A. (2015). Principles and methods of validity and reliability testing of questionnaires used in social and health science researches. Nigerian Postgraduate Medical Journal, 22(4), $195 \quad$ - 201. http://www.hpmj.org/text.asp?2015/22/4/195/173959.

Bouffard, L. (2017). Duckworth, A. (2016). Grit: The power of passion and perseverance. Toronto : HarperCollins. Revue Québécoise de Psychologie, 38(1), 285. doi:10.7202/1040080ar.

De Vera, M. J., Gavino Jr, J. C., \& Portugal, E. J. (2015). Grit and superior work performance in an Asian context. In Proceedings of 11th International Business and Social Science Research Conference, Crowne Plaza Hotel, Dubai. Retrieved from https://wbiworldconpro. com/pages/paper/dubai-conference-2015-january/2392.

Doleck, T., Bazelais, P., Lemay, D. J., Hu, X. S., Vu, A., \& Yao, J. (2018). Grit, mindset, and academic performance: A study of pre-university science students. EURASIA Journal of Mathematics, Science and Technology Education, 14(12). https://doi.org/10.29333/ejmste/94570.

Duckworth, A. L., \& Yeager, D. S. (2015). Measurement matters: Assessing personal qualities other than cognitive ability for educational purposes. Educational Research, 44, $237 \quad-\quad 251$. https://doi.org/10.3102/0013189X15584327.

Duckworth, A. L. \& Quinn, P. D. (2009). Development and validation of the short grit scale (Grit-S). Journal of 
Personality Assessment, 91(2), 166-174. https://doi.org/10.1080/00223890802634290.

Duckworth, A. L., Peterson, C., Matthews, M. D. \& Kelly, D. R. (2007). Grit: Perseverance and passion for longterm goals. Journal of Personality and Social Psychology, 92(6), 1087-1101. https://doi.org/doi:10.1037/0022-3514.92.6.1087.

Egdorf, R. L. (2013). Student engagement and student characteristics as predictors of student academic achievement at Illinois community colleges. https://doi.org/10.31274/etd-180810-3169.

Flanagan, K. M. \& Einarson, J. (2017). Gender, math confidence, and grit: Relationships with quantitative skills and achievement in an undergraduate biology course. CBE Life Sciences Education, 16(3), 47-65. http://doi.org/10.1187/cbe.16-08-0253.

Grey, L. (2019). The Impact of School-Based Mentoring on the Academic Achievement Gap. Professional School Counseling, 23(1), 2156759X1989025. https://doi.org/10.1177/2156759x19890258.

Harms, P. D. (2016). Angela Duckworth. Grit: The Power of Passion and Perseverance (Vol. 234). New York, NY: Scribner, 2016, 352 pages, \$28.00 hardcover. Personnel Psychology, 69(4), 1021-1024. https://doi.org/10.1111/peps.12198.

Ivcevic, Z., \& Brackett, M. (2014). Predicting school success: Comparing conscientiousness, grit, and emotion regulation ability. Journal of Research in Personality, 52, 29-36. https://doi.org/10.1016/j.jrp.2014.06.005.

Jacobs, J. N. (1959). Aptitude and achievement measures in predicting high school academic success. The Personnel and Guidance Journal, 37(5), 334-341. https://doi.org/10.1002/j.2164-4918.1959.tb01223.x.

Maclaren, A. S. (2015). Encountering affect: Capacities, apparatuses, conditions. Social \& Cultural Geography, 17(1), 150-152. https://doi.org/10.1080/14649365.2015.1078146.

Mason, H. D. (2018). Grit and academic performance among first-year university students: A brief report. Journal of Psychology in Africa, 28(1), 66 - 68. https://doi.org/10.1080/14330237.2017.1409478.

Muenks, K., Yang, J. S., \& Wigfield, A. (2018). Associations between grit, motivation, and achievement in high school students. Motivation Science, 4(2), 158 - 176. https://doi.org/10.1037/mot0000076.

Nelson, S. M. (2016). Grit, student engagement, and academic achievement at a historically black community college. [Unpublished doctoral thesis], University of Walden. https://scholarworks.waldenu.edu/dissertations/3189/.

Nishikawa, K., Okugami, S., \& Amemiya, T. (2015). Development of the Japanese Short Grit Scale (Grit-S). The Japanese Journal of Personality, 24(2), 167-169. https://doi.org/10.2132/personality.24.167.

Perez, M. (2015). Obtaining success: Nurturing grit in students. Journal of Interpersonal relations, Intergroup $\begin{array}{llllll}\text { relations } \quad \text { and } & \text { Identity, } & 8, & 56 & & 63 .\end{array}$ https://www.researchgate.net/publication/288344541_Obtaining_Academic_Success_Nurturing_Grit_in_St udents.

Rojas, J. P., Reser, J. A., Usher, E. L., \& Toland, M. D. (2012). Psychometric properties of the academic grit scale. Lexington: University of Kentucky.

https://sites.education.uky.edu/motivation/files/2013/08/PojasPeserTolandUsher.pdf.

Roth, R. M., Isquith, P. K., \& Gioia, G. A. (2013). Assessment of executive functioning using the behaviour rating inventory of executive function (brief). Handbook of Executive Functioning (pp. 301-331). New York: Springer. https://doi.org/10.1007/978-1-4614-8106-5_18.

Tian, H., \& Sun, Z. (2019). General Report on Students' Academic Achievement Assessment. In Assessment Report on Chinese primary school students' academic achievement (Eds.), Berlin: Heidelberg Springer. 160. https://doi.org/10.1007/978-3-662-57530-7_1.

Von Culin, K. R., Tsukayama, E., \& Duckworth, A. L. (2014). Unpacking grit: Motivational correlates of perseverance and passion for long-term goals. The Journal of Positive Psychology, 9(4), 306-312. https://doi.org/10.1080/17439760.2014.898320.

Yang, T. (2019). Student engagement in Chinese higher education institutions for the improvement of educational quality. In student engagement and quality assurance in higher education international collaborations for the enhancement of learning (Eds.), (pp. 124-135). https://doi.org/10.4324/9780429025648-10.

Wong, K. L, Ong, S. F., \& Kuek, T. Y. (2012). Constructing a survey questionnaire to collect data on service quality of business academics. European Journal of Social Sciences, 29, 209-21. http://eprints.utar.edu.my/860/1/6343.pdf. 